\title{
Supplier Selection by AHP in KMC Pharmaceutical: Use of GMIBM Method for Inconsistency Adjustment
}

\author{
Amit Yadav \\ PhD Scholar, School of Management \& Economics, \\ University of Electronics Science \& Technology of China, Chengdu, 611731, China \\ E-mail: amitaryan2u@yahoo.com
}

Gokul Bhandari

Associate Professor, Management Information Systems, Odette School of Business, University of Windsor, Ontario Canada

Daji Ergu

Assistant Professor, Southwest University for Nationalities, Chengdu, China

\section{Mohsin Ali}

PhD Scholar, School of Management \& Economics,

University of Electronics Science \& Technology of China, Chengdu, 611731, China \& International Islamic University Islamabad, Pakistan

Maira Anis

PhD Scholar, School of Management \& Economics, University of Electronics Science \& Technology of China, Chengdu, 611731, China

Received: July 4, $2015 \quad$ Accepted: August 4, $2015 \quad$ Published: October 1, 2015 doi:10.5296/jmr.v7i5.8044 URL: http://dx.doi.org/10.5296/jmr.v7i5.8044 


\section{Abstract}

The supplier selection problem is one of the most important constituent for managers. There are some influential criteria in the selection of supplier and in this paper selection of supplier includes quality, cost, service, risk management and supplier profile. However, it is frequently impossible to find a best supplier in all areas. In addition, lack of proper selection and evaluation of excels supplier can affect long term survival of firms. The contribution of this paper is in threefold. First, a geometric mean induced bias matrix (GMIBM), is used to quickly identify the most inconsistent data in the judgment matrix. This helps to preserves most of the original information in matrix, but also faster than existing models. Secondly, it solves the supplier selection process problem in a Kathmandu Medical College (KMC) pharmaceutical firm using analytic hierarchy process (AHP) model. AHP is a decision making method and considered a reliable model for supplier evaluation problem in KMC. At last, Development of Supplier Selection Process (SSP) shows the whole steps followed for supplier selection.

Keywords: Analytical Hierarchy Process (AHP), Geometric Mean Induced Bias Matrix (GMIBM), Inconsistent, Kathmandu Medical College (KMC). 


\section{Introduction}

Supplier selection has become one of the most important phases in purchasing purpose for several years. Researcher in this area had mainly focused on a variety of quantitative and qualitative aspect of decision from both short and long terms perspectives into the evaluation process. As we know that cardinal inconsistent data may exist in a judgment matrix because of the limited expertise, preference conflict and complexity nature of decision making problems. Previously different method had been used for inconsistent data processing for reciprocal matrix. Those are either complicated or dependent on the priority weights, which delays in the decision making process. Tahriri et al. (2008), "supplier selection problem has become one of the most important issues for establishing an effective supply chain system." Lee et al. (2001) and Kumara et al. (2003) accent that selection of the best supplier is an essential issue jussive mood for supply chain effectiveness and efficiency. Purchasing and supply management support the management of supplier interconnection with respect to recognition of supplier selection criteria, supplier selection decisions and supervising of supplier performance (Jose Gerardo Martínez-Martínez, 2007).

Evaluation and selection of suppliers are a typical multiple criteria decision making (MCDM) problem involving multiple criteria that can be both tangible and intangible attributes such as the traditional attributes, including quality, cost, service, flexibility and delivery performance reported in the literature (e.g., Weber, Current, \& Benton, 1991; Weber \&Ellram, 1992; Ellram, 1990; Dickson, 1966; Verma\& Pullman, 1998; Krause \&Ellram, 1997; Wilson, 1994; Min,1993; Narasimhan, 1983; Swift 1995, Soukup, 1987). The analysis for selecting and measuring the performance of supplier has been focus of many researchers and purchasing practitioner, so as to provide a comprehensive view of the important criteria in the supplier selection decision NoorulHaq and Kannan et al.(2006).

The proposed method uses the AHP model developed by Saaty (1980) for supplier selection and evaluation in a KMC pharmaceutical firm. The AHP is a multi-criteria decision making process which helps decision makers set priorities and provide best decision when both qualitative and quantitative aspect of a decision must be in consideration. AHP comprehends basic function such as structuring complexity, measuring on a rational scale and combine so as to form a complex. It is one of the powerful methods that allow the decision makers to structure complex problems in the form of a hierarchy or a set of integrated levels. Hierarchy has at least three levels; those are goal, criteria and alternatives. The goal is to select the best supplier overall. Criteria that might be used are quality, cost, delivery, and so on. Alternatives are the different offer that supplied by the supplier.

In this paper, use of geometric mean induced bias matrix (GMIBM) makes decision making process faster. GMIBM is only based on the original matrix A, is proposed to quickly identify the most inconsistent data in the judgment matrix and result shows that this model is not only faster than existing methods but also preserves most of the original information in matrix A(Ergu et al. 2012). This method can be used for any pair wise comparison matrix which deals with the consistency of the data. The most inconsistent data in a judgment matrix can be 
identified which helps in the estimation for mined cardinal inconsistent data of GMIBM and decision making can be enhanced by improving the consistency ratio of the judgment matrix.

The remaining portion of this paper is arranged as follows. Part 2 presents a brief review of literature on supplier selection and its evaluation. Part 3 is about the research methodology, case study, data collection and those data analysis, research finding. Part 4 concludes the paper.

\section{Literature}

Decision of supplier selection includes more than one selection criteria when choosing among various suppliers and criteria included in the supplier selection process may frequently belie each other (between price and quality), making decision to select the best supplier for the firm is highly complex (Mehdi et al 2007). The buyer can promote its competitive advantage in the market, if the buyer chooses the right supplier. Ellram (1990) accented that supplier selection decision needs not only to base on the traditional price and quality criteria also on longer terms and qualitative ascribes such as strategic match and rating of future manufacturing capabilities. Various models have been developed for the selection of supplier, which are based on oversimplified perceptions of decision making process (Lee et al 2001), but most of them do not consider uncertainty and complexity of decision making properly.

Kirytopoulos el al (2008) used ANP process for the selection and rating of suppliers' offers in pharmaceutical bunches. Selection of supplier criteria included in their study was cost, service, supplier's profile, quality, risk and other. In their finding they shows that quality issues dominate the decision making process for pharmaceutical industry. Their study was valuable and perceptive. However, this research is different than other in three major ways. Our case hospital is a KMC pharmaceutical supplier's selection. We amalgamated risk management as well as supplier profile that are very much important in the innovative pharmaceutical and the application of AHP model is used using GMIBM method for the inconsistency adjustment. GMIBM method previously has only been used for the emergency management to identify the most inconsistent data in a judgment matrix. This has proven that through observing and adjusting large bias data in the induced bias matrix, the consistency ratio of the judgment matrix can be quickly improved to make decision faster (Ergu et al. 2012). Furthermore, use of GMIBM method for the supplier selection can also be quickly improved to make decision faster than in comparison to the existing methods.

\section{Research Methodology}

For inquiring a coeval phenomenon within it's real life context a case study is a research strategy, when the limits between the context and phenomenon are not clearly evident and in which the multiple source of evidence are utilized (Yin, 1994). So to construct an analytical model for selecting the best supplier a case study research strategy is used.

The AHP is a decision making process to assign a priority to alternatives when multiple criteria must be conceived. This method is used by the decision makers to structure complex problems in the form of a hierarchy or set of integrated levels this method is used. As we know that the hierarchy has at least three levels such as the goal, the criteria and the 
alternatives for the supplier selection problem. Thus, the main target of this research is to develop AHP-based model for supplier selection in a KMC pharmaceutical. For both qualitative and quantitative multi criteria decision making process is used in supplier selection process. AHP method assists to rank alternatives courses, based on judgments concerning of the decision makers, the importance of the criteria and in which they met by each alternative. Therefore, AHP is suitable for the supplier selection problem (Partovi et al 1989).

The three levels of hierarchy structures are composed for supplier selection process for a KMC pharmaceutical as drawn in Figure 1. The first level (select best supplier) shows the goal for the problem mentioned, second level contains the multiple selection criteria that defines the decision making process and the third level contains contending alternative suppliers. Use of GMIBM method makes whole process faster in decision making than previous method. As Ergu (2012) have mentioned that GMIBM method quickly identifies inconsistent data (observing the largest data in induced bias matrix) and make it consistent. For positive reciprocal matrix the exiting inconsistent data processing models are complicated or dependent on the priority weights, due to which delay the decision making process occurs.

AHP Model Developed for Supplier Selection in MNC Pharmaceutical and Steps Followed Model for it:-

According to De Boer (2001), supplier selection process comprehends four major parts, such as problem definition; expression of attributes; makings of potential suppliers and at last selection of best supplier. This model obtains the pair-wise comparisons of the congener importance of measures in achieving the goals from decomposing a problem. For applying AHP method in decision making Saaty (1980, 1990 and 2000) recommended the following steps:-

a) It determines its goal and clearly defines the decision problem.

b) Gives shapes of hierarchy in different level as mentioned in Figure 1.

First goal of problem, 2nd major attributes and finally the last level of hierarchy alternatives are located. Manufacturing firms, supplier selection process and evaluation have primarily conceived criteria such as quality, service, cost, flexibility, reputation and financial stability (e.gSarkis\&Talluri, 2002; Verma\& Pullman, 1998; Hirakubo\&Kublin, 1998). This current research considered quality, cost, service, and risk management and supplier profile. 


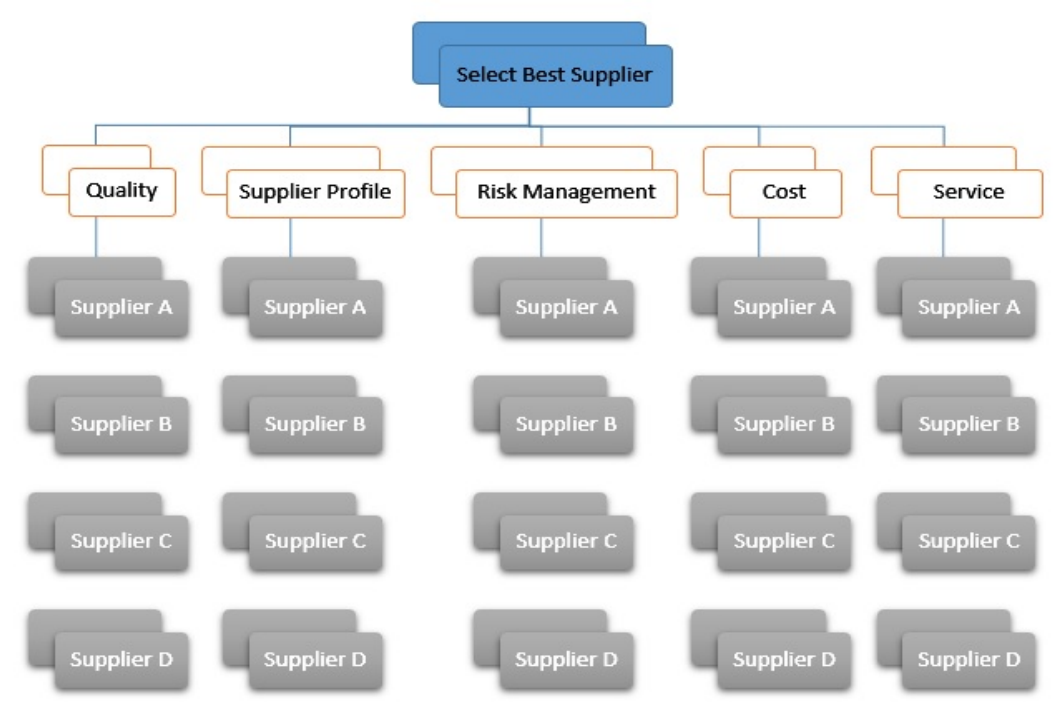

Figure 1. The Hierarchical Structure for supplier Selection

Quality

Pharmaceutical industry is the most regulated industry, quality of raw material and component requirement are very important. As FDA demands quality of drug products from manufacturers, it is necessary to select suppliers for pharmaceutical firms with supplier's certification, record of world class service and quality raw materials. Quality is the most significant attributes in supplier selection (Gonzales et al. 2004). The quality factor was measured in terms of supplier's ability to provide stimuli. Quality of product must be reliable and durable (measure of useful life of the product), having the supplier to quality systems, attachment to quality tools, percent rejection, supplier reputation and position in the market.

\section{Cost}

Purchasing and supply management literature had been considered that cost is as one of the most important aspects of supplier selection criteria. Cost is a perceptible consideration for any purchase, many researchers mentioned cost as an important factor in selecting suppliers. In ordinary usage, price is the quantity of payment or recompense for something.

Service

The service factor has been measured on the basis of importance of the service proportions in the buying firm's supplier selection. Pharmaceutical suppliers are anticipated to provide high-quality active pharmaceutical components and support services. Services include of on-time delivery, value added services and allay of communication.

\section{Risk Management (RM)}

Manage supply risk and actively palliate must be able to done by supplier's. Suppliers' help buyers' in reducing risk can positively affect cost policy, improved quality, operational ratio, improvement in process and consistency, and supply chain visibility. 


\section{Supplier Profile (SP)}

This criterion comprehends supplier's flexibility, reputation, capacity, self-certification of size, financial health, and its production facility.

c) Make a set of pair-wise comparison matrices ( $\mathrm{n} \times \mathrm{n}$ ) for each of levels. It is made such that the attributes in row $\mathrm{i}(\mathrm{i}=1,2,3,4,5 \ldots \mathrm{n})$ is ranked relative to each of the attribute represented by $\mathrm{n}$ columns. As based on relative importance of elements, pair-wise comparison is done. These assessments are then expressed in terms of Saaty scale (1 to 9 , mentioned in appendix 1, table-1).

\section{Formation of Pairwise Comparison Matrix A}

Let $\mathrm{C} 1, \mathrm{C} 2, \ldots \mathrm{Cnbe}$ the set of elements and as well as aijis the judgment on a pair of elements $\mathrm{Ci}, \mathrm{Cj}$. Using preference scale on an integer-valued 1-9 developed by Saaty (2000) for pairwise comparison the relative importance of two elements $\mathrm{Ci}, \mathrm{Cj}$ is assessed. As Saaty evaluated a value which stated that lbetween two criteria indicates that both equally influence the node, similarly 9 refers that influence of one criteria is extremely more important than other. According to this qualitative judgments and/or numerical values or intangible attributes into preference weights are transformed. From the pairwise comparison data for each element of the problem is represented by pairwise comparison matrix. AHP is used to quantify these opinions if there are $n$ items that need to be compared for a matrix, represented in $n$-by-n matrix ( $\mathrm{A}=$ aij). If $\mathrm{Ci}$ is judge as equal importance as $\mathrm{Cj}$ then aij $=1$, if $\mathrm{Ci}$ is to be more important than $\mathrm{Cj}$ then aij is greater than 1 and if $\mathrm{Ci}$ is less important than $\mathrm{Cj}$ then aij is smaller than 1. Where matrix A represents a reciprocal matrix and aij is the inverse of the akj, which shows the relative importance of $\mathrm{Ci}$ compared with attribute $\mathrm{Cj}(\mathrm{a} 12=3$ indicates that $\mathrm{C} 1$ is 3 times as important as $\mathrm{C} 2$ ). In matrix $\mathrm{A}$, it becomes the ascribing the $\mathrm{n}$ elements $\mathrm{C} 1, \mathrm{C} 2, \ldots . \mathrm{Cna}$ set of numerical weights that represents the recorded experts assessments. If matrix $\mathrm{A}$ is consistent then compute the priorities or weights of the criteria based on above information.

d) $n(n-1) / 2$ assessments are needed to create the set of matrices in step (c). In every pairwise comparison the associated reciprocals are automatically assigned.

e) To weight the eigenvectors by the weights of the criteria hierarchical synthesis is afterward distributed. Corresponding to those in the next lower level of the hierarchy the total is taken over all weighted eigenvector entries.

f) Making of all pairwise comparisons matrix than consistency test is determined by utilizing the maximum eigenvalue ( $\lambda$ max). In this paper, it is calculated by the help of Mat lab software. Where, $\lambda$ mmaxthrd $=0.1 \mathrm{RI}(\mathrm{n}-1)+\mathrm{n}$. 


\section{Macrothink}

Journal of Management Research

ISSN 1941-899X 2015, Vol. 7, No. 5

Table 1. The threshold $\lambda_{\text {nmaxthrd }}$ of the maximum eigenvalue and the corresponding RI (Adopted from Saaty (1996)

\begin{tabular}{|c|c|c|c|c|c|c|c|c|c|c|}
\hline $\mathrm{N}$ & 1 & 2 & 3 & 4 & 5 & 6 & 7 & 8 & 9 & 10 \\
\hline $\mathrm{RI}$ & 0 & 0 & 0.52 & 0.89 & 1.11 & 1.25 & 1.35 & 1.4 & 1.45 & 1.49 \\
\hline$\lambda^{\mathrm{n}}{ }_{\text {maxthrd }}$ & 1 & 2 & 3.104 & 4.267 & 5.444 & 6.781 & 7.81 & 8.98 & 10.16 & 11.341 \\
\hline
\end{tabular}

Cardinal Inconsistency

Let $A=[a i j] n \times$ nbe the judgment matrix, where aij $>0$ and aij $=1 /$ aji for all $\mathrm{i}, \mathrm{j}$, and $\mathrm{k}$, if aij=aikakjagrees for all $\mathrm{i}, \mathrm{j}$ and $\mathrm{k}$, then matrix $\mathrm{A}$ is said to be perfectly cardinal consistency. If doesn't holds than it is said to be cardinal inconsistency. In practice, it is delusive to get perfectly cardinal consistency of matrix A. So AHP gives a certain level of cardinal inconsistency of the judgment matrix. As Saaty proposed a consistency index (CI) to measure the consistency of a judgment matrix and determine certain acceptable level of inconsistency, denoted as:

$$
C I=\frac{\lambda_{\max }-n}{n-1}
$$

The consistency index (CI) was extended and consistency ratio (CR) method was further proposed by Saaty (1994) to define unique consistency test index that doesn't depend on order of judgment matrices.

$$
C R=\frac{C I}{R I}
$$

Where, $\mathrm{CI}$ is consistency index (equation 1), RI is average random index with respect to Matrix Size (Table 1).

If $\mathrm{CR} \leq 0.1=$ inconsistency is relatively small, judgment matrix is said to be acceptable inconsistency.

If $\mathrm{CR}>0.1=$ unacceptable cardinal inconsistency judgment matrix and decision maker need to revise judgments.

In order to identify the inconsistent data and make those data in consistency ratio of judgment matrix, a geometric mean induced bias matrix (GMIBM) is used in this research (Ergu et al. 2012).

\section{Geometric Mean Induced Bias Matrix (GMIBM)}

This method helps to identify the inconsistent data in the judgment matrix by observing the largest data in the induced bias matrix. Ergu (2012) has explained related theorems and corollaries in detail. Summarize inconsistency identification and adjustment process of GMIBM is presented below. 
Step I (Inconsistency Identification)

Step-1: Calculate a column matrix L and row matrix R, those are composed of geometric means of row and columns (judgment matrix) respectively.

$$
\left\{\begin{array}{l}
L=\left(\sqrt[n]{\prod_{k=1}^{n} a_{1 k}}, \cdots \sqrt[n]{\prod_{k=1}^{n} a_{i k}}, \cdots \sqrt[n]{\prod_{k=1}^{n} a_{j k}}, \cdots \sqrt[n]{\prod_{k=1}^{n} a_{n k}}\right)^{T} \\
R=\left(\sqrt[n]{\prod_{k=1}^{n} a_{k 1}}, \cdots \sqrt[n]{\prod_{k=1}^{n} a_{k i}}, \cdots \sqrt[n]{\prod_{k=1}^{n} a_{k j}}, \cdots \sqrt[n]{\prod_{k=1}^{n} a_{k n}}\right)^{\prime}
\end{array}\right.
$$

Step-2: Compute geometric mean matrix.

$$
\bar{A}=L \times R=\left(\sqrt[n]{\prod_{k=1}^{n} a_{i k} a_{k j}}\right)_{n \times n}
$$

Step-3: Calculate geometric mean induced bias matrix (GMIBM) C,

$$
C=\bar{A} \circ A^{T}=\left(c_{i j}\right)=\left(\bar{a}_{i j} \cdot a_{j i}\right)=\left(\sqrt[n]{\prod_{k=1}^{n} a_{i k} a_{k j}} \cdot a_{j i}\right)
$$

Step-4: Than find out the largest value in matrix $C$, which denoted as $C_{i j}^{\max }$ and deviating from 1. The value founded $a_{i j}$ is considered as most inconsistent data in matrix A. If there is another data in matrix $\mathrm{C}$, deviating from 1 , then their corresponding value in matrix A can also be considered as the possible inconsistent element. But for adjustment, need to take maximum value deviating from 1 .

After inconsistent data are known then following steps are followed to adjust the inconsistent data.

\section{Step II (Inconsistency Adjustment)}

1. Calculate the value founded inconsistent from above analysis.

$$
\widetilde{a}_{i j}=\sqrt[n-2]{\prod_{k=1, \neq i, j}^{n} a_{i k} a_{k j}}=\sqrt[n-2]{\frac{\bar{a}_{i j}^{n}}{a_{i j}^{2}}}=\bar{a}_{i j}\left(\frac{\bar{a}_{i j}}{a_{i j}}\right)^{\frac{2}{n-2}}
$$

Where, $\tilde{a}=$ estimated value of the most inconsistent data aij

$\bar{a}_{i j}=$ geometric mean value located at the $\mathrm{i}^{\text {th }}$ row and $\mathrm{j}^{\text {th }}$ column of geometric mean matrix $\bar{A}$ 
2. Use the revised value in matrix A by replacing the inconsistent data. Continue the steps till judgment matrix is consistent.

In brief, the process followed for inconsistency adjustment by GMIBM has two major steps (1stinconsistency identification and 2nd inconsistency adjustment). Steps I shows procedure for computing geometric mean of matrix $\bar{A}$. Sometimes while following the inconsistent adjustment, we get the adjusted value more than Saaty measurement value. For such condition, if value is more than 9 or less than $1 / 9$ then it needs to consider as 9 or $1 / 9$ respectively (to make value within Saaty scale) and follow the steps again.

\section{The Case Study}

The proposed model is used for the analysis of supplier selection process in KMC. In order to maintain confidentiality of supplier, we have used here supplier name as A, B, C and D. $\mathrm{KMC}$ is one of the top medical college and hospital in Nepal. It has more than 1000 employees, different field doctors and pharmaceutical shops for the supply of medicine to patient. For this pharmaceutical, there are four main suppliers (A, B, C and D) and their demand of medicine is high due to high patient treatment purpose. Pharmaceutical shops demand is of tablets, capsules, injectable, ointments, inhalants, solutions and some other. This hospital deals with major and minor disease and therapy. Out of those suppliers, some of them are Nepali company and some are Indian company. So to get the market hold, there is competition market for the supplier. They have different way of giving benefit to the consumer but overall the perfect supplier is target to choose from this research.

Before applying the AHP, KMC had not any standard method used for rating suppliers and didn't consider risk management and supplier profile. They only used their oral view regarding quality, cost and services to choose the suppliers.

\section{Data Collection and Analysis}

Table 2. Pairwise Comparison Matrix for the five criteria

\begin{tabular}{|c|c|c|c|c|c|}
\hline & Quality & Cost & Service & Risk Management & Supplier Profile \\
\hline Quality & 1 & 1 & 3 & 4 & 7 \\
\hline Cost & 1 & 1 & 5 & 4 & 9 \\
\hline Service & 0.3333 & 0.2000 & 1 & 3 & 3 \\
\hline Risk Management & 0.2500 & 0.2500 & 0.3333 & 1 & 4 \\
\hline Supplier Profile & 0.1430 & 0.1111 & 0.3333 & 0.2500 & 1 \\
\hline Column total & 2.7263 & 2.5610 & 9.6666 & 12.250 & 24.000 \\
\hline
\end{tabular}

To assess the order of importance of the supplier selection criteria a survey questionnaire approach was used for gathering the data. From the hierarchy structure in figure 1, we constructed a questionnaire to enable pairwise comparison matrix between all the criteria.

In a specific comparison with respect to Saaty's 1-9 scale, the pairwise comparison process arouses qualitative judgments that indicate the strength of a group of decision maker's 
druthers. For the result, questionnaire survey method was used as input for the AHP and it took a total of 10 judgments (i.e. 5(5-1)/2) to complete the pairwise comparisons shown in Table 2. The other entries of data are 1 along the diagonal and the reciprocal of the 10 judgments. To derive estimation of the criteria priorities the data shown in the matrix can be positioned and those positioned data provide a measure of the relative importance of each criterion. Basically, the following three steps are followed to combine as to form a pairwise comparison matrix.

a) Do sum of the elements in each column.

b) Then divide each value of matrix by its column sum.

c) Find out the priority vector by computing row averages.

Below Table 3 shows the synthesized matrix for the five supplier selection criteria.

Table 3. Normalized Matrix for the Five Criteria $(\mathrm{CR}=0.0562<0.1)$

\begin{tabular}{|c|c|c|c|c|c|}
\hline & Quality & Cost & Service & Risk Management & Supplier Profile \\
\hline Quality & 0.3668 & 0.3904 & 0.3103 & 0.3265 & 0.2917 \\
\hline Cost & 0.3668 & 0.3904 & 0.5172 & 0.3265 & 0.3750 \\
\hline Service & 0.1223 & 0.0781 & 0.1034 & 0.2449 & 0.1250 \\
\hline Risk Management & 0.0917 & 0.0976 & 0.0345 & 0.0816 & 0.1667 \\
\hline Supplier Profile & 0.0525 & 0.0434 & 0.0345 & 0.0204 & 0.0417 \\
\hline $\begin{array}{c}\text { Weights Row } \\
\text { Average }\end{array}$ & 0.3371 & 0.3952 & 0.1347 & 0.0944 & 0.0385 \\
\hline \multicolumn{7}{|c|}{ Total } & 1 \\
\hline
\end{tabular}

For example here shown that how we find out the weights row average for quality: $(1 / 2.7263$ $+1 / 2.5610+3 / 9.6666+4 / 12.250+7 / 24) / 5=0.3371$. Similarly for cost, service, risk management and supplier profile is also calculated (shown in table 3). From this table, it shows that cost is the best supplier selection criteria with respect to quality, service, supplier profile and risk-management. After data adjustment (inconsistent data to consistent) with the help of GMIBM method (appendix 2), $\mathrm{CR}=0.0562<0.1$.

Table 4-8 shows four suppliers with respect to each criterion implemented the pairwise comparison matrices. The procedure used to create the criteria comparison matrix is similar to this process. 


\section{Macrothink}

Table 4. Pairwise Comparison Weights with respect to Quality

\begin{tabular}{|c|c|c|c|c|}
\hline & Supplier A & Supplier B & Supplier C & Supplier D \\
\hline Supplier A & 0.5060 & 0.4615 & 0.5217 & 0.5385 \\
\hline Supplier B & 0.1687 & 0.1538 & 0.1304 & 0.1538 \\
\hline Supplier C & 0.2530 & 0.3077 & 0.2609 & 0.2308 \\
\hline Supplier D & 0.0728 & 0.0769 & 0.0869 & 0.0769 \\
\hline $\begin{array}{c}\text { Weights Row } \\
\text { Average }\end{array}$ & 0.5069 & 0.1517 & 0.2631 & 0.0784 \\
\hline \multicolumn{3}{|c|}{ Total } \\
\hline
\end{tabular}

Table 5. Pairwise Comparison Weights with respect to Cost

\begin{tabular}{|c|c|c|c|c|}
\hline & Supplier A & Supplier B & Supplier C & Supplier D \\
\hline Supplier A & 0.5000 & 0.5333 & 0.5217 & 0.4000 \\
\hline Supplier B & 0.1250 & 0.1333 & 0.1304 & 0.2000 \\
\hline Supplier C & 0.2500 & 0.2667 & 0.2609 & 0.3000 \\
\hline Supplier D & 0.1250 & 0.0667 & 0.0869 & 0.1000 \\
\hline $\begin{array}{c}\text { Weights Row } \\
\text { Average }\end{array}$ & 0.4887 & 0.1472 & 0.2694 & 0.0947 \\
\hline \multicolumn{4}{|c|}{ Total } \\
\hline
\end{tabular}

Table 6. Pairwise Comparison Weights with respect to Service

\begin{tabular}{|c|c|c|c|c|}
\hline & Supplier A & Supplier B & Supplier C & Supplier D \\
\hline Supplier A & 0.4615 & 0.5217 & 0.4091 & 0.3333 \\
\hline Supplier B & 0.2308 & 0.2609 & 0.4091 & 0.2222 \\
\hline Supplier C & 0.1538 & 0.0869 & 0.1364 & 0.3333 \\
\hline Supplier D & 0.1538 & 0.1304 & 0.0454 & 0.1111 \\
\hline $\begin{array}{c}\text { Weights Row } \\
\text { Average }\end{array}$ & 0.4314 & 0.2807 & 0.1776 & 0.1102 \\
\hline \multicolumn{4}{|c|}{ Total } \\
\hline
\end{tabular}


Table 7. Pairwise Comparison Weights with respect to Risk Management

\begin{tabular}{|c|c|c|c|c|}
\hline & Supplier A & Supplier B & Supplier C & Supplier D \\
\hline Supplier A & 0.5000 & 0.4444 & 0.2222 & 0.3333 \\
\hline Supplier B & 0.2500 & 0.2222 & 0.4444 & 0.1667 \\
\hline Supplier C & 0.5000 & 0.1111 & 0.2222 & 0.3333 \\
\hline Supplier D & 0.2500 & 0.2222 & 0.1111 & 0.1667 \\
\hline $\begin{array}{c}\text { Weights Row } \\
\text { Average }\end{array}$ & 0.3749 & 0.2708 & 0.2917 & 0.1875 \\
\hline \multicolumn{7}{|c|}{ Total } \\
\hline
\end{tabular}

Table 8. Pairwise Comparison Weights with respect to Supplier Profile

\begin{tabular}{|c|c|c|c|c|}
\hline & Supplier A & Supplier B & Supplier C & Supplier D \\
\hline Supplier A & 0.5625 & 0.5769 & 0.5294 & 0.5454 \\
\hline Supplier B & 0.1875 & 0.1923 & 0.2941 & 0.1818 \\
\hline Supplier C & 0.0625 & 0.0385 & 0.0588 & 0.0909 \\
\hline Supplier D & 0.1875 & 0.1923 & 0.1176 & 0.1818 \\
\hline $\begin{array}{c}\text { Weights Row } \\
\text { Average }\end{array}$ & 0.5535 & 0.2139 & 0.0627 & 0.1698 \\
\hline \multicolumn{7}{|c|}{ Total } \\
\hline
\end{tabular}

This means, purchasing managers compare each pair of suppliers with respect to each criterion (quality, cost, service, supplier profile and risk management). The three steps procedure previously mentioned is used to determine the weights of the suppliers for each criterion.

\section{Computation of weights}

The final solution using AHP analysis method and result is shown in Table 9. To compute overall weights, simple weighted average technique is followed. Five weights are computed for a given supplier, one for each rating criteria (from table 4-8). The appropriate criteria weights in meeting the goals of the hierarchy are multiplied by these four weights (Table 3). The results of five criteria multiplications are added together to find out supplier score. The computed total benefit to be obtained from selecting this supplier represents each supplier score. The calculations for computing total weights of supplier are as follows:

Total weight of supplier A,

$=(0.3371)(0.5069)+(0.3952)(0.4887)+(0.1347)(0.4314)+(0.0944)(0.3749)+(0.0385)(0.5535)$

$=0.4788$ 


\section{Macrothink}

Table 9. Weighted Supplier Alternatives

\begin{tabular}{lcccccc}
\hline & $\begin{array}{c}\text { Quality } \\
(0.3371)\end{array}$ & $\begin{array}{c}\text { Cost } \\
(0.3952)\end{array}$ & $\begin{array}{c}\text { Service } \\
(0.1347)\end{array}$ & $\begin{array}{c}\text { Risk Management } \\
(0.0944)\end{array}$ & $\begin{array}{c}\text { Supplier Profile } \\
(0.0385)\end{array}$ & Weights \\
& & & & & $+(0.5535)$ & $=0.4788$ \\
$\mathrm{~S}_{\mathrm{A}}$ & $(0.5069)$ & $+(0.4887)$ & $+(0.4314)$ & $+(0.3749)$ & $+(0.2139)$ & $=0.1809$ \\
$\mathrm{~S}_{\mathrm{B}}$ & $(0.1517)$ & $+(0.1472)$ & $+(0.2807)$ & $+(0.2708)$ & $+(0.0627)$ & $=0.2485$ \\
$\mathrm{~S}_{\mathrm{C}}$ & $(0.2617)$ & $+(0.2694)$ & $+(0.1776)$ & $+(0.2917)$ & $+(0.1698)$ & $=0.1029$ \\
$\mathrm{~S}_{\mathrm{D}}$ & $(0.0784)$ & $+(0.0947)$ & $+(0.1102)$ & $+(0.1875)$ & \multicolumn{3}{c}{ Total } & 1 \\
\hline
\end{tabular}

According to result of the overall weights of alternative suppliers, supplier A (0.4788) is most favored followed by supplier $C(0.2485)$, supplier $B(0.1809)$ and supplier D (0.1029) respectively. Where, $\mathrm{S}_{\mathrm{A}}=$ supplier $\mathrm{A}>\mathrm{S}_{\mathrm{C}}=$ supplier $\mathrm{C}>\mathrm{S}_{\mathrm{B}}=$ supplier $\mathrm{B}>\mathrm{S}_{\mathrm{D}}=$ supplier D.So, according to result supplier $\mathrm{A}$ is decided to be the best supplier.

\section{Supplier Selection Process Developed}

Figure 2 explains the process followed for supplier selection in this research. From this development of steps, author believed that whole process become more easy to understand and can be implemented for any purchasing firm to make their decision.

In brief, at first the selection criteria need to be listed and identified. Then according to that the hierarchical structure is built. The judgment matrix is not consistent most of the time due to lack of decision making process. So, GMIBM method is followed to make inconsistent data to consistent. This step is revised until the judgment matrix becomes consistent. After this find solution to the problem and rank the suppliers. Select the best supplier with respect to result than negotiate and agree with the supplier. At last sign a contract with supplier. If deal with supplier is not agreed than again rank supplier and sign a contract. 


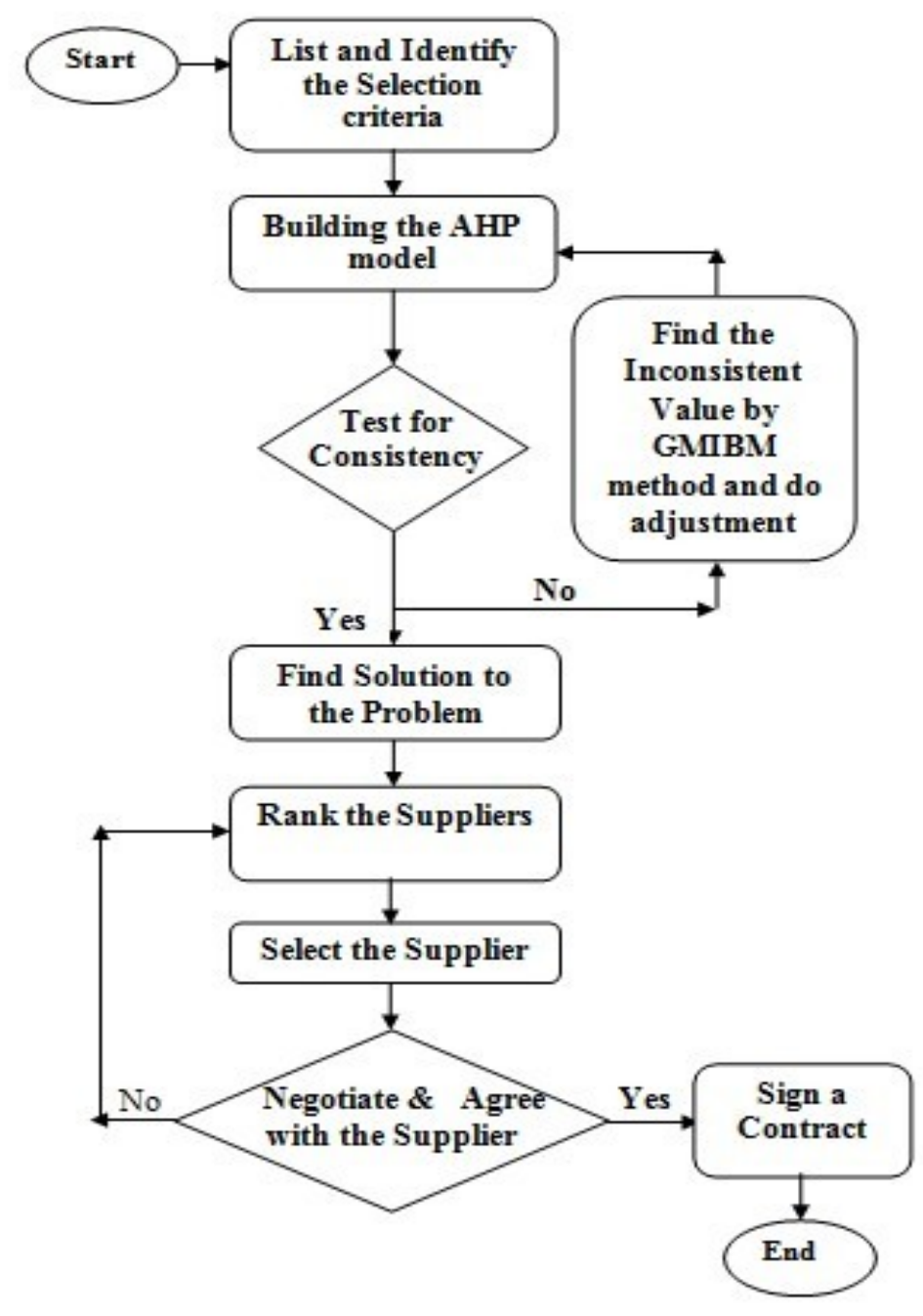

Figure 2. Steps followed for Supplier Selection Process (SSP)

\section{Conclusion and Entailment}

Supplier selection problem is one of the major problems for any purchasing firm and since 1960s researchers are interested in these issues. For that AHP is an important approach as for it helps for decision makers in choosing best suppliers established on relative attributes. The AHP based supplier selection is used for ranking suppliers in KMC pharmaceutical. AHP approach helps on the decision makers subjective judgments regarding the importance of the attributes to rank alternative suppliers. To make the process easy and quick identification of inconsistent data, GMIBM method is used. The development of Supplier Selection Process (SSP) was achieved to show the whole steps followed for supplier selection problem. SSP process proves that it can be used as effective selection tool for selecting the best supplier. The quintessential aspect of strategic purchasing and supply chain management than can affect manufacturing firm is selecting and evaluating best supplier. The main objective of supplier selection is to lower risk, reduce cost, better quality, on time delivery and better 
service. From this research analysis, it concludes that if KMC pharmaceutical will make contract with supplier A (0.4788) than can get more benefit and success.

\section{References}

De Boer, L., Labro, E., \& Molrlacchi. (2001). A Review of methods supporting supplier selection. European Journal of Purchasing and Supply Management, 7, 75-89.

Dickson, G.W. (1966). An analysis of supplier selection systems and decisions. Journal of Purchasing, 2(1), 5-17

D.Ergu, G.Kou, Y. Peng, \& Y. Shi (2012). Data Consistency in Emergency Management. INT J COMPUT COMMUN, 7(3), 450-458. ISSN 1841-9836, http://dx.doi.org/10.15837/ijccc.2012.3.1386

Ellram, L.M. (Fall 1990). The supplier selection decision in strategic partnership. Journal of Purchasing and Materials Management, 26(4), 8-14.

F.Y. Partovi, J. Burton, \& A. Banarjee. (1989). Application of Analytical Hierarchy Process in Operation Management," International Journal of Operations and Production Management, 10(3), 5-19.

González, M. E., Quesada, G., \& Mora Monge, C. (2004). determining the importance of the supplier selection process in manufacturing: a case study. International Journal of Physical Distribution \& Logistics Management, 34(6), 492-504

Hirakubo, N., \& Kublin, M. (1998). The relative importance of supplier selection criteria: The case of electronic components. International Journal of Purchasing \& Materials Management, 34(2), 19-24. http://dx.doi.org/10.1111/j.1745-493X.1998.tb00044.x

José, M., J. G. (Fall 2007). Use of an alternative decision support system in vendor selection decisions. Inter Metro Business Journal, 3(2), 1-4.

Kirytopoulos, K., Leopoulos, V., \& Voulgaridou, D. (2008). Supplier selection in pharmaceutical industry: an analytic network process approach. Benchmarking: An International Journal, 15(4), 494-516.

Krause, D. R., \& Ellram, L. M. (1997). Success factors in supplier development. International Journal of Physical Distribution and Logistics Management, 27, 39- 52.

Kumara, M., Vratb, P., \& Shankarc, R. (2003). A fuzzy goal programming approach for vendor selection problem in a supply chain. Computers and Industrial Engineering, 46, $69-85$.

Lee, E-K., Ha, S., \& Kim, S-K. (2001). Supplier Selection and Management System Considering Relationships in Supply Chain Management. IEEE Transactions on Engineering Management, 47(4), 307-318. 


\section{I Macrothink}

Journal of Management Research ISSN 1941-899X 2015, Vol. 7, No. 5

Lin, C. Chow, W. S., Madu, C. N., Kuei, C., \& Yu, P. (2005). A structural equation model of supply chain quality management and organizational performance. International Journal of Production Economics, 96(3), 355-365. http://dx.doi.org/10.1016/j.ijpe.2004.05.009

Min, H. (1993). International supplier selection: a multi-attribute utility approach. International Journal of Physical Distribution and Logistics Management, 24, 24-33. http://dx.doi.org/10.1108/09600039410064008

Mehdi Fasanghari, Shooresh Mohammadi, Mehdi Khodaei, Ali Abdollahi, \& Farzad Habibipour Roudsari. (2007). A Conceptual Framework for impact of information Technology on Supply Chain Management. in International Conference on Convergence Information Technology (ICCIT 2007) Korea: IEEE computer society, 72-76. http://doi.ieeecomputersociety.org/10.1109/ICCIT.2007.385

Narasimhan, R. (1983). An analytical approach to supplier selection. Journal of Purchasing and Materials Management, 27-32.

NoorulHaq, A., \& G. Kannan. (2006). Fuzzy analytical hierarchy process for evaluating and selecting a vendor in a supply chain model. Int. J. Adv. Manuf. Technol., 29, 826-835. http://dx.doi.org/10.1007/s00170-005-2562-8

Saaty, T.L. (1980). The Analytic Hierarchy Process. New York: McGraw-Hall.

Saaty, T. L. (1990). How to make a decision: The analytic hierarchy process. European Journal of Operational Research, 48, 9-26.

Saaty, T.L. (1994). How to Make a Decision: The Analytic Hierarchy Process. Interfaces, 24, $19-43$.

Saaty, T. L. (2000). Fundamentals of decision making and priority theory with the analytic hierarchy process. Pittsburgh, PA: RWS Publications.

Sarkis, J., \& Talluri, S. (2002). A model for strategic supplier selection. Journal of Supply Chain Management, 38(1), 18-28. http://dx.doi.org/10.1111/j.1745-493X.2002.tb00117.x

Soukup, W. (1987). Supplier selection strategies. Journal of Purchasing and Materials Management, 23(2), 7-12

Swift, C. O. (1995). Preferences for single sourcing and supplier selection criteria. Journal of Business Research, 32(2), 105-111.

Tahriri, F., Rasid Osman, M. R., Ali, A., \& MohdYusuff, R. (2008). A review of supplier selection methods in manufacturing industries. Suramaree Journal of Science Technology, 15(3), 201-208.

Verma, R., \& Pullman, M. E. (1998). An analysis of the supplier selection process. Omega, International Journal of Management Science, 26, 739-750. http://dx.doi.org/10.1016/S0305-0483(98)00023-1 
Weber, C. A., Current, J. R., \& Benton, W. C. (1991). Vendor Selection Criteria and Methods. European Journal of Operational Research, 50, 2-18. http://dx.doi.org/10.1016/0377-2217(91)90033-R

Weber, C. A., \& Ellram, L. M. (1992). Supplier Selection using Multi-Objective Programming: A Decision Support System Approach. International Journal of Physical $\begin{array}{llll}\text { Distribution } \quad \text { and } \quad \text { Logistics } & \text { 3-14. }\end{array}$ http://dx.doi.org/10.1108/09600039310038161

Wilson, E. J. (1994). The relative importance of supplier selection criteria: A review and Update. International Journal of Purchasing \& Materials Management, 30(3), 35-41.

Yin, R. K. (1994). Case Study Research: Design and Methods, 2nd ed. Sage, Thousand Oaks, CA.

\section{APPENDIX-1}

\section{Supplier Selection in a Generic Pharmaceutical Firm Survey Questionnaire}

Dear:

My name is I am a student of Management Science and Engineering, School of Management and Economics, University of Electronic Science and Technology, Chengdu, Sichuan, China.

I am writing to arouse your opinion as an expert on supplier selection and evaluation. I am investigating the opinions of purchasing managers by means of a survey questionnaire.

This questionnaire leverages Analytic Hierarchy Process (AHP) to model supplier selection in your KMC (Kathmandu Medical College) and hospital pharmaceutical supply chain. As an expert on purchasing and supply management, your opinion will be significantly invaluable to this research.

\section{Brief Background}

In today's competitive market, costs of sourcing commodities from suppliers have become more than ever significant. Supplier selection represents one of the most essential purchasing decisions which can determine the long term sustainability of a firm. In this context, the intent of this research is to apply a multi-criteria analysis by a three-level AHP, to select the best supplier for participation in a KMC (Kathmandu Medical College) and hospital pharmaceutical supply chain. Level 1 represents the ultimate goal the decision maker intends to achieve in supplier selection problem; Level 2 entails the supplier selection criteria including quality, cost, service, risk management and supplier profile and Level 3 represents prequalified suppliers including suppliers A-D. 


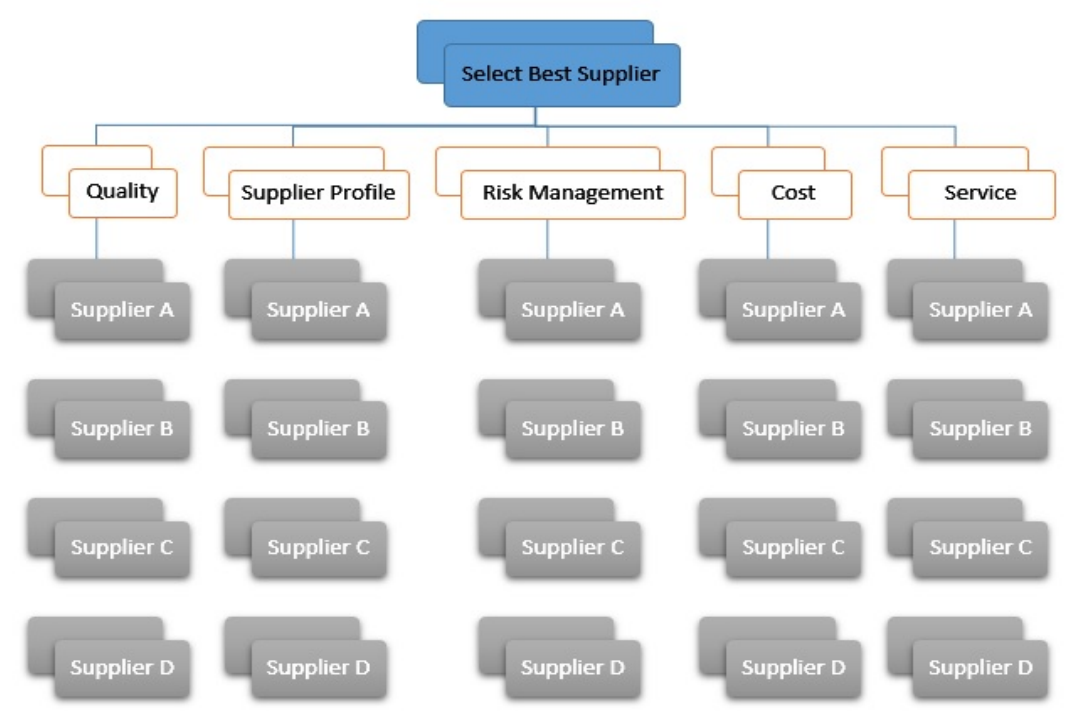

Figure 1:- The Hierarchical Structure for supplier Selection

For your opinion as an expert, the pair-wise comparison scale by Saaty, reported in Table 1, can be used to assess or express the importance of one element over another.

\section{Quality}

Pharmaceutical industry is the most regulated industry, so the quality of raw material and component requirement are very important. As FDA demands quality of drug products from manufacturers, it is necessary to select suppliers for pharmaceutical firms with supplier's certification, record of world class service and quality raw materials. Quality is the most significant attributes in supplier selection (Gonzales et al. 2004). The quality factor was measured in terms of supplier's ability to provide stimuli. That must be reliable and durable (measure of useful life of the product), having the supplier to quality systems, attachment to quality tools, percent rejection and supplier reputation and position in the market.

\section{Cost}

Cost has traditionally been considered as one of the most important aspects of supplier selection criteria in the purchasing and supply management literature. Cost is aperceptible consideration for any purchase, and many researchers mentioned cost as an important factor in selecting suppliers. In ordinary usage, price is the quantity of payment or recompense for something.

\section{Service}

The service factor has been measured on the basis of importance of the service proportions in the buying firm's supplier selection. Pharmaceutical suppliers are anticipated to provide high-quality active pharmaceutical components and support services. Services include of on-time delivery, value added services and allay of communication. 


\section{Risk Management (RM)}

Manage supply risk and actively palliate must be able to done by supplier's. As suppliers help buyers reduce risk can positively affect cost policy, improved quality, operational ratio, improvement in process and consistency, and supply chain visibility.

\section{Supplier Profile (SP)}

This criterion comprehends supplier's flexibility, reputation, capacity, self-certification of size, financial health, and its production facility.

Table 1. Scale of preference between two elements (Adopted from Saaty)

\begin{tabular}{|l|l|l|}
\hline $\begin{array}{l}\text { Preference Weights/ } \\
\text { Level of Importance }\end{array}$ & Definition & Explanation \\
\hline 1 & $\begin{array}{l}\text { Equally } \\
\text { preferred }\end{array}$ & $\begin{array}{l}\text { Two activities contribute equally to } \\
\text { the objective }\end{array}$ \\
\hline 3 & Moderately & $\begin{array}{l}\text { Experience and judgment slightly } \\
\text { favor one activity over another }\end{array}$ \\
\hline 5 & Strongly & $\begin{array}{l}\text { Experience and judgment strongly or } \\
\text { essentially favor one activity over } \\
\text { another }\end{array}$ \\
\hline 7 & Very strongly & $\begin{array}{l}\text { An activity is strongly favored over } \\
\text { another and its dominance } \\
\text { demonstrated in practice }\end{array}$ \\
\hline 9 & Extremely & $\begin{array}{l}\text { The evidence favoring one activity } \\
\text { over another is of the highest degree } \\
\text { possible of affirmation }\end{array}$ \\
\hline $2,4,6,8$ & $\begin{array}{l}\text { Intermediate } \\
\text { values }\end{array}$ & $\begin{array}{l}\text { Used to represent compromise } \\
\text { between the preferences listed above }\end{array}$ \\
\hline
\end{tabular}




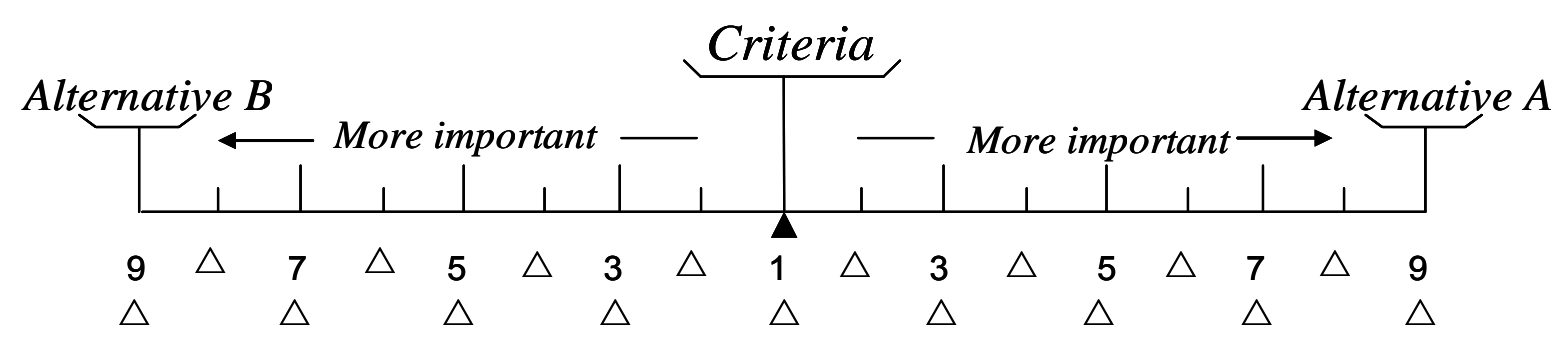

Note: 1 - Equal importance ; 3 - Weak importance ; 5 - Strong importance ;

7 - Demonstrated importance; 9-Absolute importance;

2,4,6,8 - Intermediate values between the two adjacent judgments

Tick " $\sqrt{ }$ " the corresponding score in the symbol " $\Delta$ "

\section{PLEASE SEE EXAMPLES BELOW}

Please mark or tick $(\checkmark)$ the criteria number (code) that you assess more or equal important than other, with respect to the goal: "selection of best supplier" and express on the verbal scale the importance of the more or equal important criteria over the other.

If you mark or circle " 5 " in the following question, means that "cost" is 5 times more important in your expert opinion than the "quality."

\begin{tabular}{|l|l|l|l|l|l|l|l|l|l|l|l|l|l|l|l|l|l|l|l|}
\hline 1 & Quality & 9 & 8 & 7 & 6 & 5 & 4 & 3 & 2 & 1 & 2 & 3 & 4 & $5 \checkmark$ & 6 & 7 & 8 & 9 & Cost \\
\hline
\end{tabular}

Conversely, marking or circling the number " 1 " in the following question, means that "quality" is as important as "cost."

\begin{tabular}{|l|l|l|l|l|l|l|l|l|l|l|l|l|l|l|l|l|l|l|l|}
\hline 2 & Quality & 9 & 8 & 7 & 6 & 5 & 4 & 3 & 2 & $1 \checkmark$ & 2 & 3 & 4 & 5 & 6 & 7 & 8 & 9 & Cost \\
\hline
\end{tabular}

Moreover, marking or circling " 4 " in the following question means that "quality" is 4 times more important than the "cost."

\begin{tabular}{|l|l|l|l|l|l|l|l|l|l|l|l|l|l|l|l|l|l|l|l|}
\hline 3 & Quality & 9 & 8 & 7 & 6 & 5 & $4 \checkmark$ & 3 & 2 & 1 & 2 & 3 & 4 & 5 & 6 & 7 & 8 & 9 & Cost \\
\hline
\end{tabular}

It's my opinion that the above examples are very helpful. Please contribute your expert opinion by marking $(X)$ or cycling $(\mathrm{O})$ for your choice of number.

\section{Major Risk Criteria or Factors}

Question1. Please mark or circle the criteria number (code) that you assess more or equal important than other, with respect to the goal: "to select the best supplier." 


\section{1) Macrothink}

\begin{tabular}{|l|l|l|l|l|l|l|l|l|l|l|l|l|l|l|l|l|l|l|l|}
\hline 1 & Quality & 9 & 8 & 7 & 6 & 5 & 4 & 3 & 2 & 1 & 2 & 3 & 4 & 5 & 6 & 7 & 8 & 9 & Cost \\
\hline 2 & Quality & 9 & 8 & 7 & 6 & 5 & 4 & 3 & 2 & 1 & 2 & 3 & 4 & 5 & 6 & 7 & 8 & 9 & Service \\
\hline 3 & Quality & 9 & 8 & 7 & 6 & 5 & 4 & 3 & 2 & 1 & 2 & 3 & 4 & 5 & 6 & 7 & 8 & 9 & $\begin{array}{l}\text { Risk } \\
\text { Management }\end{array}$ \\
\hline 4 & Quality & 9 & 8 & 7 & 6 & 5 & 4 & 3 & 2 & 1 & 2 & 3 & 4 & 5 & 6 & 7 & 8 & 9 & $\begin{array}{l}\text { Supplier } \\
\text { Profile }\end{array}$ \\
\hline 5 & Cost & 9 & 8 & 7 & 6 & 5 & 4 & 3 & 2 & 1 & 2 & 3 & 4 & 5 & 6 & 7 & 8 & 9 & \begin{tabular}{l} 
Service \\
\hline 6
\end{tabular} \\
\hline Cost & 9 & 8 & 7 & 6 & 5 & 4 & 3 & 2 & 1 & 2 & 3 & 4 & 5 & 6 & 7 & 8 & 9 & $\begin{array}{l}\text { Risk } \\
\text { Management }\end{array}$ \\
\hline 7 & Cost & 9 & 8 & 7 & 6 & 5 & 4 & 3 & 2 & 1 & 2 & 3 & 4 & 5 & 6 & 7 & 8 & 9 & $\begin{array}{l}\text { Supplier } \\
\text { Profile }\end{array}$ \\
\hline 8 & Service & 9 & 8 & 7 & 6 & 5 & 4 & 3 & 2 & 1 & 2 & 3 & 4 & 5 & 6 & 7 & 8 & 9 & $\begin{array}{l}\text { Risk } \\
\text { Management }\end{array}$ \\
\hline 9 & Service & 9 & 8 & 7 & 6 & 5 & 4 & 3 & 2 & 1 & 2 & 3 & 4 & 5 & 6 & 7 & 8 & 9 & $\begin{array}{l}\text { Supplier } \\
\text { Profile }\end{array}$ \\
\hline 10 & $\begin{array}{l}\text { Risk } \\
\text { Management }\end{array}$ & 9 & 8 & 7 & 6 & 5 & 4 & 3 & 2 & 1 & 2 & 3 & 4 & 5 & 6 & 7 & 8 & 9 & $\begin{array}{l}\text { Supplier } \\
\text { Profile }\end{array}$ \\
\hline
\end{tabular}

\section{Alternative suppliers}

Question2. Please mark or circle the alternative number (code) that you assess more or equal important than other, with respect to criterion "quality."

\begin{tabular}{|l|l|l|l|l|l|l|l|l|l|l|l|l|l|l|l|l|l|l|l|}
\hline 1 & Supplier A & 9 & 8 & 7 & 6 & 5 & 4 & 3 & 2 & 1 & 2 & 3 & 4 & 5 & 6 & 7 & 8 & 9 & Supplier B \\
\hline 2 & Supplier A & 9 & 8 & 7 & 6 & 5 & 4 & 3 & 2 & 1 & 2 & 3 & 4 & 5 & 6 & 7 & 8 & 9 & Supplier C \\
\hline 3 & Supplier A & 9 & 8 & 7 & 6 & 5 & 4 & 3 & 2 & 1 & 2 & 3 & 4 & 5 & 6 & 7 & 8 & 9 & Supplier D \\
\hline 4 & Supplier B & 9 & 8 & 7 & 6 & 5 & 4 & 3 & 2 & 1 & 2 & 3 & 4 & 5 & 6 & 7 & 8 & 9 & Supplier C \\
\hline 5 & Supplier B & 9 & 8 & 7 & 6 & 5 & 4 & 3 & 2 & 1 & 2 & 3 & 4 & 5 & 6 & 7 & 8 & 9 & Supplier D \\
\hline 6 & Supplier C & 9 & 8 & 7 & 6 & 5 & 4 & 3 & 2 & 1 & 2 & 3 & 4 & 5 & 6 & 7 & 8 & 9 & Supplier D \\
\hline
\end{tabular}




\section{MInstitute ${ }^{\text {Math }}$}

Question3. Please mark or circle the alternative number (code) that you assess more or equal important than other, with respect to criterion "cost"

\begin{tabular}{|l|l|l|l|l|l|l|l|l|l|l|l|l|l|l|l|l|l|l|l|}
\hline 1 & Supplier A & 9 & 8 & 7 & 6 & 5 & 4 & 3 & 2 & 1 & 2 & 3 & 4 & 5 & 6 & 7 & 8 & 9 & Supplier B \\
\hline 2 & Supplier A & 9 & 8 & 7 & 6 & 5 & 4 & 3 & 2 & 1 & 2 & 3 & 4 & 5 & 6 & 7 & 8 & 9 & Supplier C \\
\hline 3 & Supplier A & 9 & 8 & 7 & 6 & 5 & 4 & 3 & 2 & 1 & 2 & 3 & 4 & 5 & 6 & 7 & 8 & 9 & Supplier D \\
\hline 4 & Supplier B & 9 & 8 & 7 & 6 & 5 & 4 & 3 & 2 & 1 & 2 & 3 & 4 & 5 & 6 & 7 & 8 & 9 & Supplier C \\
\hline 5 & Supplier B & 9 & 8 & 7 & 6 & 5 & 4 & 3 & 2 & 1 & 2 & 3 & 4 & 5 & 6 & 7 & 8 & 9 & Supplier D \\
\hline 6 & Supplier C & 9 & 8 & 7 & 6 & 5 & 4 & 3 & 2 & 1 & 2 & 3 & 4 & 5 & 6 & 7 & 8 & 9 & Supplier D \\
\hline
\end{tabular}

Question4. Please mark or circle the alternative number (code) that you assess more or equal important than other, with respect to criterion "Service."

\begin{tabular}{|l|l|l|l|l|l|l|l|l|l|l|l|l|l|l|l|l|l|l|l|}
\hline 1 & Supplier A & 9 & 8 & 7 & 6 & 5 & 4 & 3 & 2 & 1 & 2 & 3 & 4 & 5 & 6 & 7 & 8 & 9 & Supplier B \\
\hline 2 & Supplier A & 9 & 8 & 7 & 6 & 5 & 4 & 3 & 2 & 1 & 2 & 3 & 4 & 5 & 6 & 7 & 8 & 9 & Supplier C \\
\hline 3 & Supplier A & 9 & 8 & 7 & 6 & 5 & 4 & 3 & 2 & 1 & 2 & 3 & 4 & 5 & 6 & 7 & 8 & 9 & Supplier D \\
\hline 4 & Supplier B & 9 & 8 & 7 & 6 & 5 & 4 & 3 & 2 & 1 & 2 & 3 & 4 & 5 & 6 & 7 & 8 & 9 & Supplier C \\
\hline 5 & Supplier B & 9 & 8 & 7 & 6 & 5 & 4 & 3 & 2 & 1 & 2 & 3 & 4 & 5 & 6 & 7 & 8 & 9 & Supplier D \\
\hline 6 & Supplier C & 9 & 8 & 7 & 6 & 5 & 4 & 3 & 2 & 1 & 2 & 3 & 4 & 5 & 6 & 7 & 8 & 9 & Supplier D \\
\hline
\end{tabular}

Question5. Please mark or circle the alternative number (code) that you assess more or equal important than other, with respect to criterion "risk management."

\begin{tabular}{|l|l|l|l|l|l|l|l|l|l|l|l|l|l|l|l|l|l|l|l|}
\hline 1 & Supplier A & 9 & 8 & 7 & 6 & 5 & 4 & 3 & 2 & 1 & 2 & 3 & 4 & 5 & 6 & 7 & 8 & 9 & Supplier B \\
\hline 2 & Supplier A & 9 & 8 & 7 & 6 & 5 & 4 & 3 & 2 & 1 & 2 & 3 & 4 & 5 & 6 & 7 & 8 & 9 & Supplier C \\
\hline 3 & Supplier A & 9 & 8 & 7 & 6 & 5 & 4 & 3 & 2 & 1 & 2 & 3 & 4 & 5 & 6 & 7 & 8 & 9 & Supplier D \\
\hline 4 & Supplier B & 9 & 8 & 7 & 6 & 5 & 4 & 3 & 2 & 1 & 2 & 3 & 4 & 5 & 6 & 7 & 8 & 9 & Supplier C \\
\hline 5 & Supplier B & 9 & 8 & 7 & 6 & 5 & 4 & 3 & 2 & 1 & 2 & 3 & 4 & 5 & 6 & 7 & 8 & 9 & Supplier D \\
\hline 6 & Supplier C & 9 & 8 & 7 & 6 & 5 & 4 & 3 & 2 & 1 & 2 & 3 & 4 & 5 & 6 & 7 & 8 & 9 & Supplier D \\
\hline
\end{tabular}




\section{Macrothink}

Question6. Please mark or circle the alternative number (code) that you assess more or equal important than other, with respect to criterion "supplier profile."

\begin{tabular}{|l|l|l|l|l|l|l|l|l|l|l|l|l|l|l|l|l|l|l|l|}
\hline 1 & Supplier A & 9 & 8 & 7 & 6 & 5 & 4 & 3 & 2 & 1 & 2 & 3 & 4 & 5 & 6 & 7 & 8 & 9 & Supplier B \\
\hline 2 & Supplier A & 9 & 8 & 7 & 6 & 5 & 4 & 3 & 2 & 1 & 2 & 3 & 4 & 5 & 6 & 7 & 8 & 9 & Supplier C \\
\hline 3 & Supplier A & 9 & 8 & 7 & 6 & 5 & 4 & 3 & 2 & 1 & 2 & 3 & 4 & 5 & 6 & 7 & 8 & 9 & Supplier D \\
\hline 4 & Supplier B & 9 & 8 & 7 & 6 & 5 & 4 & 3 & 2 & 1 & 2 & 3 & 4 & 5 & 6 & 7 & 8 & 9 & Supplier C \\
\hline 5 & Supplier B & 9 & 8 & 7 & 6 & 5 & 4 & 3 & 2 & 1 & 2 & 3 & 4 & 5 & 6 & 7 & 8 & 9 & Supplier D \\
\hline 6 & Supplier C & 9 & 8 & 7 & 6 & 5 & 4 & 3 & 2 & 1 & 2 & 3 & 4 & 5 & 6 & 7 & 8 & 9 & Supplier D \\
\hline
\end{tabular}

Once again, thank you so much for your time and for offering your effort.

\section{APPENDIX-2}

Data Analysis using GMIBM process for inconsistency adjustment

I) Pairwise Comparison Matrix and Computations: (Evaluation Criteria):- Detail steps of solution.

A) Original Matrix

\begin{tabular}{|c|c|c|c|c|c|}
\hline & Quality & Cost & Service & Risk Management & Supplier Profile \\
\hline Quality & 1 & 1 & 3 & 4 & 1 \\
\hline Cost & 1 & 1 & 5 & 4 & 3 \\
\hline Service & $1 / 3$ & $1 / 5$ & 1 & 3 & 3 \\
\hline Risk Management & $1 / 4$ & $1 / 4$ & $1 / 3$ & 1 & 4 \\
\hline Supplier Profile & 1 & $1 / 3$ & $1 / 3$ & $1 / 4$ & 1 \\
\hline
\end{tabular}

$\mathrm{A}=$

$\begin{array}{lllll}1.0000 & 1.0000 & 3.0000 & 4.0000 & 1.0000 \\ 1.0000 & 1.0000 & 5.0000 & 4.0000 & 3.0000 \\ 0.3333 & 0.2000 & 1.0000 & 3.0000 & 3.0000 \\ 0.2500 & 0.2500 & 0.3333 & 1.0000 & 4.0000 \\ 1.0000 & 0.3333 & 0.3333 & 0.2500 & 1.0000\end{array}$

$\mathrm{d}=\operatorname{eigs}(\mathrm{A})=\operatorname{maxeigs}=6.0522>\lambda_{\text {maxthrd }}(5.444)($ Using Mat lab)

$\mathrm{CI}=\frac{(\lambda \max -\mathrm{n})}{(\mathrm{n}-1)}=(6.0522-5) / 4=0.2631$

$\mathrm{CR}=\frac{C I}{R I}=0.2631 / 1.11=0.2370>0.1$ (it is inconsistent) 
a) Inconsistency Identification

$\mathrm{A}=$

$\begin{array}{lllll}1.0000 & 1.0000 & 3.0000 & 4.0000 & 1.0000 \\ 1.0000 & 1.0000 & 5.0000 & 4.0000 & 3.0000 \\ 0.3333 & 0.2000 & 1.0000 & 3.0000 & 3.0000 \\ 0.2500 & 0.2500 & 0.3333 & 1.0000 & 4.0000 \\ 1.0000 & 0.3333 & 0.3333 & 0.2500 & 1.0000\end{array}$

$\mathrm{L}_{1}=\sqrt[5]{(1 * 1 * 3 * 4 * 1)}=1.644$

$\mathrm{L}=[1.644,2.268,0.903,0.608,0.488]$

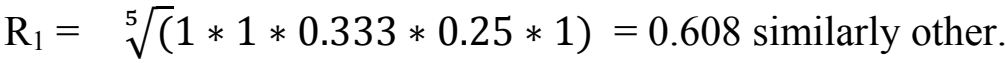

$\mathrm{R}=[0.608,0.441,1.107,1.644,2.048]$

$\bar{A}=\mathrm{L} * \mathrm{R}$

$\bar{A}=$

$\begin{array}{lllll}0.9996 & 0.7250 & 1.8199 & 2.7027 & 3.3669 \\ 1.3789 & 1.0002 & 2.5107 & 3.7286 & 4.6449 \\ 0.5490 & 0.3982 & 0.9996 & 1.4845 & 1.8493 \\ 0.3697 & 0.2681 & 0.6731 & 0.9996 & 1.2452 \\ 0.2967 & 0.2152 & 0.5402 & 0.8023 & 0.9994\end{array}$

$\mathrm{A}^{\prime}$

$\begin{array}{lllll}1.0000 & 1.0000 & 0.3333 & 0.2500 & 1.0000 \\ 1.0000 & 1.0000 & 0.2000 & 0.2500 & 0.3333 \\ 3.0000 & 5.0000 & 1.0000 & 0.3333 & 0.3333 \\ 4.0000 & 4.0000 & 3.0000 & 1.0000 & 0.2500 \\ 1.0000 & 3.0000 & 3.0000 & 4.0000 & 1.0000\end{array}$

$\mathrm{C}=\mathrm{L}^{*} \mathrm{R} * \mathrm{~A}^{\prime}$

$\begin{array}{lllll}1.0000 & 0.7250 & 0.6060 & 0.6760 & 3.3670 \\ 1.3789 & 1.0000 & 0.5020 & 0.9320 & 1.5480 \\ 1.6470 & 1.9900 & 1.0000 & 0.4950 & 1.6160 \\ 1.4790 & 1.0720 & 2.0190 & 1.0000 & 0.3110 \\ 0.2970 & 0.6460 & 1.6210 & 3.2090 & 1.0000\end{array}$

$\mathrm{C}_{15}{ }^{\text {max }}=3.367$ (maximum value deviating from 1 ) 


\section{a) Inconsistency Adjustment}

$\widetilde{a}_{i j}=\sqrt[n-2]{\prod_{k=1, \neq i, j}^{n} a_{i k} a_{k j}}=\sqrt[n-2]{\frac{\bar{a}_{i j}^{n}}{a_{i j}^{2}}}=\bar{a}_{i j}\left(\frac{\bar{a}_{i j}}{a_{i j}}\right)^{\frac{2}{n-2}}$

$\mathrm{a}_{15}=\sqrt[5-2]{\left(\frac{3.3669^{5}}{1^{\wedge} 2}\right)}=7.56=$ approximately 7

Now, replacing the value of $A$ by replacing the inconsistent elements $\mathrm{a}_{15}$ and $\mathrm{a}_{51}$ with 7 and $1 / 7$ respectively.

$\mathrm{A}=$

$\begin{array}{lllll}1.0000 & 1.0000 & 3.0000 & 4.0000 & 7.0000 \\ 1.0000 & 1.0000 & 5.0000 & 4.0000 & 3.0000 \\ 0.3333 & 0.2000 & 1.0000 & 3.0000 & 3.0000 \\ 0.2500 & 0.2500 & 0.3333 & 1.0000 & 4.0000 \\ 0.1430 & 0.3333 & 0.3333 & 0.2500 & 1.0000\end{array}$

$\mathrm{d}=\operatorname{eigs}(\mathrm{A})=$ maxeigs $=5.4907>\lambda_{\max t h r d}(5.444)$

$\mathrm{CI}=\frac{(\lambda \max -\mathrm{n})}{(\mathrm{n}-1)}=(5.4907-5) /(5-1)=0.12267$

$\mathrm{CR}=\frac{C I}{R I}=0.12267 / 1.11=0.11>0.1$ (it is inconsistent)

\section{a') Inconsistency Identification}

$\mathrm{A}=$

$\begin{array}{lllll}1.0000 & 1.0000 & 3.0000 & 4.0000 & 7.0000 \\ 1.0000 & 1.0000 & 5.0000 & 4.0000 & 3.0000 \\ 0.3333 & 0.2000 & 1.0000 & 3.0000 & 3.0000 \\ 0.2500 & 0.2500 & 0.3333 & 1.0000 & 4.0000 \\ 0.1430 & 0.3333 & 0.3333 & 0.2500 & 1.0000\end{array}$

$\mathrm{L}_{1}=\sqrt[5]{(}(1 * 1 * 3 * 4 * 7)=2.426$

$\mathrm{L}=[2.426,2.268,0.903,0.608,0.331]$

$\mathrm{R}_{1}=\sqrt[5]{(1 * 1 * 0.333 * 0.25 * 0.1430)}=0.012$ similarly other.

$\mathrm{R}=[0.412,0.441,1.107,1.644,3.022]$ 
$\mathrm{A}^{---}=\mathrm{L}^{*} \mathrm{R}$

$\begin{array}{lllll}0.9995 & 1.0699 & 2.6856 & 3.9883 & 7.3314 \\ 0.9344 & 1.0002 & 2.5107 & 3.7286 & 6.8539 \\ 0.3720 & 0.3982 & 0.9996 & 1.4845 & 2.7289 \\ 0.2505 & 0.2681 & 0.6731 & 0.9996 & 1.8374 \\ 0.1364 & 0.1460 & 0.3664 & 0.5442 & 1.0003\end{array}$

$\mathrm{A}^{\prime}$

$\begin{array}{lllll}1.0000 & 1.0000 & 0.3333 & 0.2500 & 0.1430 \\ 1.0000 & 1.0000 & 0.2000 & 0.2500 & 0.3333 \\ 3.0000 & 5.0000 & 1.0000 & 0.3333 & 0.3333 \\ 4.0000 & 4.0000 & 3.0000 & 1.0000 & 0.2500 \\ 7.0000 & 3.0000 & 3.0000 & 4.0000 & 1.0000\end{array}$

$\mathrm{C}=\mathrm{L}^{*} \mathrm{R} * \mathrm{~A}^{\prime}$

$\begin{array}{lllll}1.0000 & 1.0699 & 0.8940 & 0.9970 & 1.0480\end{array}$

$\begin{array}{lllll}0.9344 & 1.0000 & 0.5020 & 0.9320 & 2.2820 \\ 1.1160 & 1.9910 & 1.0000 & 0.4940 & 0.9090 \\ 1.0020 & 1.0720 & 2.0190 & 1.0000 & 0.4590 \\ 0.9550 & 0.4380 & 1.0990 & 2.1770 & 1.0000\end{array}$

$\mathrm{C}_{25}{ }^{\max }=2.282$ (maximum value deviating from 1 )

\section{b') Inconsistency Adjustment}

$\widetilde{a}_{i j}=\sqrt[n-2]{\prod_{k=1, \neq i, j}^{n} a_{i k} a_{k j}}=\sqrt[n-2]{\frac{\bar{a}_{i j}^{n}}{a_{i j}^{2}}}=\bar{a}_{i j}\left(\frac{\bar{a}_{i j}}{a_{i j}}\right)^{\frac{2}{n-2}}$

$\mathrm{a}_{25}=\sqrt[5-2]{\left(\frac{6.8539^{5}}{3^{\wedge} 2}\right)}=11.88=$ approximately 12 (It is beyond Saaty's 9-point scale. In order to follow Saaty's 9-point scale, we take this value as Saaty's 9-point scale maximum (9) value and do again analysis)

Now, replacing the value of $A$ by replacing the inconsistent elements $a_{25}$ and $a_{52}$ with 9 and $1 / 9$ respectively.

$\mathrm{A}=$

$\begin{array}{lllll}1.0000 & 1.0000 & 3.0000 & 4.0000 & 7.0000 \\ 1.0000 & 1.0000 & 5.0000 & 4.0000 & 9.0000 \\ 0.3333 & 0.2000 & 1.0000 & 3.0000 & 3.0000 \\ 0.2500 & 0.2500 & 0.3333 & 1.0000 & 4.0000 \\ 0.1430 & 0.1110 & 0.3333 & 0.2500 & 1.0000\end{array}$

Column total $=\begin{array}{lllll}2.7263 & 2.5610 & 9.6666 & 12.250 & 24.000\end{array}$ 
$\mathrm{d}=$ eigs $(\mathrm{A})=$ maxeigs $=5.2496<\lambda_{\operatorname{maxthrd}}(5.444)$

$\mathrm{CI}=\frac{(\lambda \mathrm{max}-\mathrm{n})}{(\mathrm{n}-1)}=(5.2496-5) /(5-1)=0.0624$

$\mathrm{CR}=\frac{C I}{R I}=0.0624 / 1.11=0.0562<0.1$ (so, now it is consistent) .

Similarly, rest of the solution is done. 